\title{
Encephalomyelitis responsive to ganciclovir
}

\author{
Anderson R.B. Paiva, Samira L. Apóstolos-Pereira, Leandro T. Lucato, \\ Luís R. Machado, Paulo E. Marchiori, Milberto Scaff
}

A 19-year-old previously healthy boy was admitted with a ten-day history of rapidly progressive urinary retention, constipation, ascending hypoesthesia up to the thoracic level and gait instability. On physical examination, he presented fever, tetraparesis, brisk reflexes, multidirectional nystagmus, right-side Horner's syndrome. CSF: 225 cells $/ \mathrm{mm}^{3}$ (15\% neutrophils), protein $142 \mathrm{mg} / \mathrm{dl}$, glucose $46 \mathrm{mg} / \mathrm{dl}$. MRI: Fig 1. Acute demyelinating encephalomyelitis was diagnosed and the patient was treated with high doses of corticosteroids for five days. Despite CSF improvement after corticosteroid treatment, clear signs of clinical worsening were observed. Anti-CMV (IgG and (gM) antibodies were detected in the CSF, and this justified empirical treatment with ganciclovir, starting one week after the corticosteroids. In one month, the patient was able to stand and walk with canes. MRI showed complete recovery (Fig 2).

Fig 1. Initial MRI study, T2weighted, in the sagittal $[\mathrm{A}]$ and axial [B] planes: bright lesions at the cranial-cervical transition and $\mathrm{C} 5$-C7 vertebral levels (arrows in A). There was no contrast enhancement. Axial image demonstrates a central spinal cord lesion (arrow head in B).

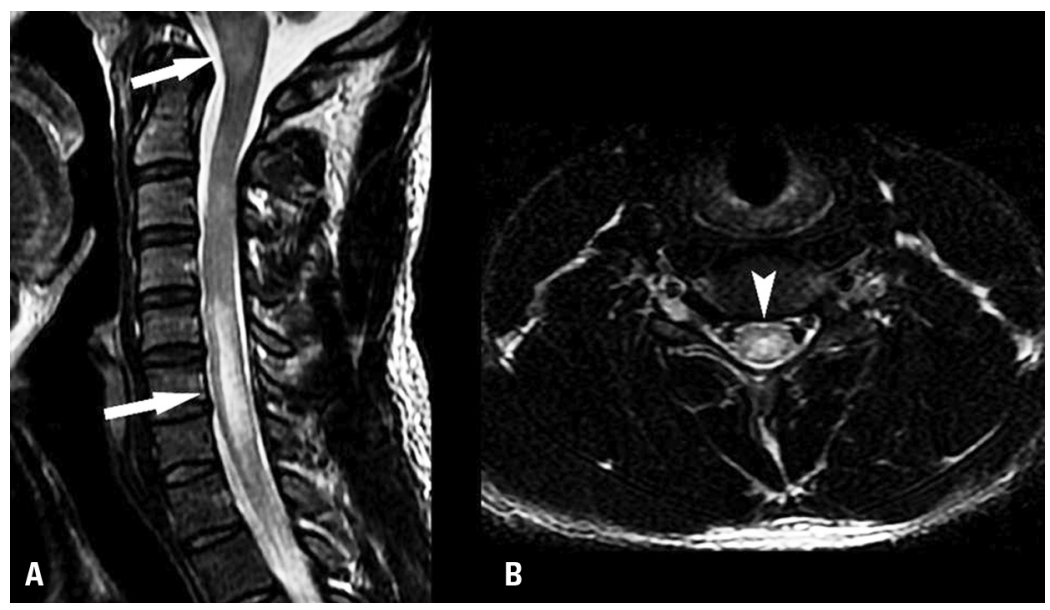

Fig 2. Follow-up MRI produced 42 days later showed complete resolution of the lesions, as shown in T2-weighted sagittal $[A]$ and axial $[B]$ images.

\section{Correspondence}

Anderson Rodrigues Brandão Paiva Rua Dr. Ovídio Pires de Campos 171 / 104 05403-010 São Paulo SP - Brasil

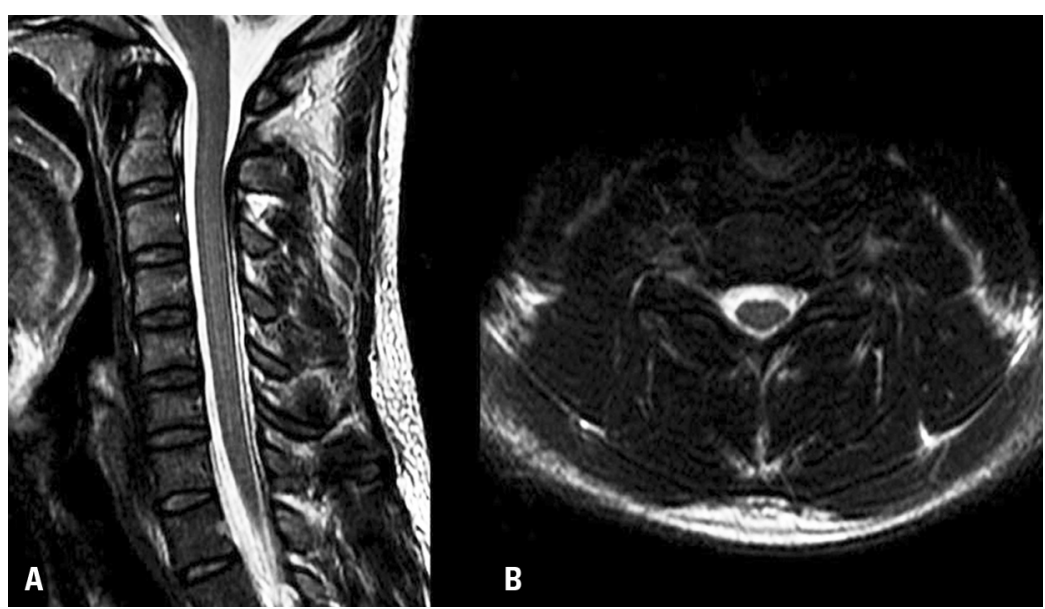

Received 29 March 2010

Received in final form 11 April 2010 Accepted 19 April 2010

\section{ENCEFALOMIELITE COM RESPOSTA TERAPÊUTICA AO GANCICLOVIR}

Department of Neurology and Institute of Radiology, Medical School, University of São Paulo, São Paulo SP, Brazil. 